\title{
Gender and The Modern Organization, Ten Years After
}

\section{Lena Abrahamsson'}

Professor, Human Work Science, Luleå University of Technology, Sweden

\begin{abstract}
This empirical article presents a gender analysis of long-term impacts of some of the many organizational change projects in Swedish industrial work organizations during the 1990s. Based on the results of return visits to three industrial companies and their change projects (implementation of Lean Production or other modern organizational models) that I studied more than a decade earlier, I discuss how the work organizations eventually had changed and specifically how and whether organizational internal gender patterns had changed. The initial study showed genderbased restoring responses to strategic organizational changes, especially in the gender-segregated and gender-homogeneous work organizations. These responses conserved gender patterns as well as the organizations' culture in general, resulting in less productive work as well as a problematic work environment. The follow-up study showed that the organizations slowly changed according to the modern organizational models (e.g., Lean Production), but at the same time, in some cases, keeping the same gender segregation and stereotypical gender markings of skills and work tasks or with new variants of unequal gender order. In addition, the follow-up study showed other and more positive results with emerging pattern of gender equality, at least in the form of reduced gender segregation and less stereotypical ideas concerning gender. The material indicates that the studied companies, in some aspects, developed into less gendered production organizations while taking some steps toward a modern organization and this was done without gender equality interventions. Therefore, the material indicated that, at least in part, gender equality could be seen as a prerequisite or perhaps even a side effect of modern organizational concepts. This article contributes to the emerging literature on an organizational theory of undoing gender as well as to the research of conditions and consequences of the modern organizational models.
\end{abstract}

\section{KEY WORDS}

Gender, gender equality / Lean Production / Modern organizational models / Organization / Organizational change / Restoring mechanisms / Undoing gender

\section{Introduction}

U

hat are the long-term effects of "modern organizational models", such as Lean Production, on the possibilities to create effective and good work organizations for both women and men? What do these kinds of organizational changes mean for gender equality ${ }^{1}$ in Swedish working life in the long run? One way to find answers to these questions is to explore the connections between such organizational changes and gender. Since work organizations are deeply gendered (latent as well as explicit), there are connections between gender and organization when it also comes to changes-both in the change processes and in the effects/results from the change processes. Drawing on empirical results from both initial visits and ten-year follow-up visits of three Swedish industrial companies (two from the pulp and paper industry and one from the electronics

\footnotetext{
${ }^{1}$ E-mail: lena.abrahamsson@ltu.se
} 
industry), I discuss some of these connections from two directions. First, I examine what happens with the implementation of modern organizational models such as Lean Production and its eventual effects when implemented in different types of gender-equal or -unequal work organizations. Second, I examine what happens with an organization's internal gender patterns and "gender equality" when an industrial company implements Lean Production. More precisely, this article examines how structures and social constructions of gender affect these companies' planned organizational changes and how these organizational changes affect structures and social constructions of gender. These two processes together are important parts of the foundation for gender equality or gender inequality. The ten-year follow-up with the same companies allows for a long-term perspective on both gender and the modern organization. What happens in a longer time perspective? Can we see more or less gender equality at the workplaces inside the work organizations?

This article takes its point of departure from the ongoing discussions in working life research on the contradicting effects of the modern organizational models. On the one hand, modern organizational models, at least some of them and parts of them, seem to hinder or even create resistance to a good work environment and sustainable work organizations as well as for gender equality (Abrahamsson 2000, 2002). On the other hand, there are other, more positive signs, such as the current and gradually growing movements in Swedish industrial companies toward gender equality and toward a modern organization. In many ways, these two positive movements are separate and mutually independent processes, but these trends make it tempting to ask these questions: Could it be that gender equality and at least parts of a modern organization are connected or perhaps even interdependent? Can a modern organization encourage gender equality in work organizations? So easy, it is of course not, but inspired by the emerging literature on an organizational theory of undoing gender (Ely and Meyerson 2010). I will try to take a positive turn, by basing the discussions more on gender equality instead of gender inequality or gender status quo.

\section{Method}

The focus in this article is not gender equality interventions or approaches nor organizational change methods; instead, this article discusses the companies' planned and strategic organizational changes and the modern organizational models that underlie these organizational changes, such as Lean Production, and how these organizational models and changes influence gender patterns. The empirical material comes from two studies—one initial and one follow-up-conducted ten years apart. ${ }^{2}$

\section{The initial study: A gender analysis of organizational change projects in industrial companies}

The initial study was part of a larger research project conducted 15 years ago (Abrahamsson 2000, 2002, 2009). That research project critically explored how different types of gendered organizations affected companies' organizational change projects and also how processes of gender segregation took form and were socially constructed in 
relation to the organizational changes. I studied strategic organizational change projects at eight Swedish companies in the pulp and paper industry, the electronics industry, the food industry, and the laundry industry. All the change projects were top-down driven. I followed these companies and their respective change projects between 1994 and 1998. The empirical core was interviews with 16 women industrial workers and observations I conducted at their workplaces. In total, I conducted 78 interviews with 59 individuals (30 women and 29 men) who were workers, project leaders, or managers.

I categorized the studied companies into three types based on the distribution of women and men. This strategy was inspired by Kanter's (1977) conclusions that numbers matter and Thurén's (2000) work on the force, range, and hierarchy of the gender order. Gendering, for example, can be stronger or weaker, more or less extensive, and more or less unequal. In some cases, gender may be irrelevant (Deutsch 2007). My main approach assumed that work organizations can be more or less gendered and in different ways and that this gendering affects the individual's possibilities as well as the organizations' functionality in the short run as well as in the long run (Kvande and Rasmussen 1995). The three groups also represent more or less common types of industrial work organizations in Sweden: (1) an almost completely male-homogeneous production organization (i.e., an organization where more than $90 \%$ of the workers are men and most jobs have a natural mark as male); (2) a gender-segregated production organization (i.e., an organization with a relatively equal number of men and women (40-60\%), but built on gender stereotypes and gender segregation, symbolically as well as practically); and (3) a gender-mixed production organization (i.e., an organization with a relatively equal number of men and women (40-60\%), but with women and men working side-by-side and performing the same type of work tasks and no obvious gender marking). ${ }^{3}$

\section{The follow-up study: what happened ten years after?}

The follow-up study-mainly conducted during 2004 and 2005 and funded by the Swedish Governmental Agency for Innovation Systems (VINNOVA)—was part of a program intended to analyze experiences from the gender equality initiatives in Swedish working life undertaken during the 1980s and 1990s. More than ten researchers, of whom I was one, were given the task of revisiting their old projects to find answers to the following question: "What happened afterward?" (Göransson and Sundin 2006). My contribution to this was a follow-up study that included return visits, ten years after the initial study, to three of the previously studied eight companies-two pulp and paper companies (identified as the Kraftliner Factory and the Napkin Factory) and one electronics company (identified as the Opto-fiber Factory). These three companies were chosen because they represented the three types or groups from the initial study: (1) the Kraftliner Factory had an almost completely male-homogeneous production organization; (2) the Napkin Factory had a gender-segregated production organization; and (3) the Opto-fiber Factory had a gender-mixed production organization. The follow-up study was conducted during 2004-2005. The empirical material is based on 14 interviews with workers, project leaders, and managers (many of them the same persons as in the initial study), three company visits and observations, and company personnel statistics. I developed and compared both before and after descriptions in both quantitative and qualitative terms. The purpose of the follow-up was to find out what had happened with 
the restoration processes, with the organizations' attempts to implement a modern organization model, and with the different types of gendered organizations and processes of gender segregation. As I mentioned in the introduction, I wanted to see whether gender segregation or gender hierarchy was reduced and whether other signs of more gender equality were present. In the reading of the results, it can also be important to note that the follow-up study was not designed as a replication of the initial study and that the social context and the spirit of the age naturally were different.

\section{Background}

\section{Gender patterns in Swedish working life-both positive and negative tendencies}

Working life in Sweden as well as in the other Nordic countries is usually described as characterized by a powerful discourse on gender equality and a long tradition of concrete and rather successful gender equality interventions although also having a stable and highly gender-segregated labor market (Korvajärvi 2011; Martin 2011). Recently, it seems as something has happened. As of late, there are many signs of more gender equality in the Swedish labor market. Although the evidence of more gender equality is sometimes subtle, involving isolated pockets of gender equality or variations in gender inequality, it is also possible to see broader positive trends (Grönlund 2014). This article, in addition to the above stated goals, examines what can be learned from these positive developments. A new report from the Swedish Government Delegation for Gender Equality in the Working Life (Abrahamsson and Gonäs 2014) presents several such trends. For example, one positive trend is gender segregation in the labor market has decreased. Sweden is no longer among the most gender-segregated countries in Europe. The wage gap has decreased, although it is slow, and there is an increased proportion of women in higher education, in managerial positions, and in "classic" male-dominated industries and occupations. In addition, more men are employed in jobs traditionally seen as female: health services and social care professions (although men are not being employed in these "female" jobs as much as women are being employed in "male" jobs). Another positive trend is that the best jobs seem to be in mixed-gender occupations. Here, employees have a better work environment, better health, higher wages, higher skill requirements, flexible working hours, and better opportunities to combine work with family responsibilities.

In addition, Swedish industrial companies, trade organizations, and VINNOVA and similar research funding agencies show a growing interest in gender equality interventions based on social-constructionist and radical-structuralist gender theory (i.e., something quite close to what Ely and Meyerson (2000) and Meyerson and Kolb (2000) call "changes from the fourth frame-resisting and revising the dominant discourse"). In Sweden, this is called action-oriented or applied gender research (cf., Andersson and Amundsdotter 2010; Franzén et al. 2010; Wikberg-Nilsson et al. 2009, 2010). This approach involves both critiques and experimentations and builds on localized processes of incremental change where organization members identify and disrupt oppressively gendered social practices and revise them (Ely and Meyerson 2000). This approach often includes the idea that it is possible to do interventions that enhance both gender 
equality and business goals (Bailyn 2011; Benschop and Verloo 2011; Franzén et al. 2010; Kantola and Squires 2012; Petersson McIntyre 2014).

However, we can also note that the reduced gender segregation mostly can be seen in specific contexts, such as in larger cities and in occupations that require tertiary education qualifications or new types of occupations and perhaps also including just some groups of women and men. In other contexts in Sweden, such as some rural and old industrial areas, over the past ten years gender segregation has even increased. In the largest section of the labor market with traditional occupations that require less educational qualifications (e.g., production workers in large industrial companies), the gender patterns have mainly remained unchanged in recent decades (SCB 2007; Löfström 2004). It is from this part of working life that the empirical material in this article is gathered. In these areas, both gender-homogeneous work organizations (e.g., male-dominated) and strictly gender-segregated organizations are evident. A general increase in the level of technical proficiency and an improved working environment seems to have not changed the gender pattern. Gender segregation still gives different work conditions for women and men (Abrahamsson and Gonäs 2014). At some of the companies in the initial study (in the early 1990s), the women machine operators had monotonous and repetitive jobs that probably caused more musculoskeletal injuries and long-term sick. Many of the women workers saw the planned new organization as a way for them to improve their working conditions.

\section{"The modern organization"}

Before continuing the discussion, it is also important to contextualize the studied companies' change projects in relation to the discourse associated with the concept of "the modern organization." This discourse, based in management theories, assumes that organizations are fundamentally stable and that change can be planned and implemented. During the 1980s and 1990s, many popular management models spread across the industrial world (Furusten 1999; Røvik 2003): Lean Production, Total Quality Management, Learning Organization, The Boundaryless Organization, and The Individualized Organization. Although some of these concepts originated in Japan, their more prominent advocates were US researchers and consultants (Furusten 1999). The models were somewhat different, but they built on one another and had clear normative management messages and tools marketed as ready for use in all types of organizations. In Swedish industrial practice, these new management ideas were mixed with neoliberal views, old national labor market traditions (such as IF Metall's "the good work" (1985) and "the Swedish labor market model"), as well as research on workplace learning, ergonomics, and sociotechnical principles (Abrahamsson and Johansson 2013; Karlsson 2013), an amalgamation of ideas that have formed a Swedish or rather a Nordic version (Abrahamsson and Sederblad 2013; Johansson and Abrahamsson 2009).

In the initial study, all the companies were inspired by the international management rhetoric of the 1990s. Even if the projects were not specifically called, for example, Lean Production, they were typical examples of the first wave of Lean Production (cf., Björkman and Lundqvist 2013). Not surprisingly, the companies' organizational change projects were very similar, all aiming for better product quality and organizational efficiency by organizing production from order to customer, visualizing orderliness, 
providing shorter lead times, reducing waste, minimizing production bottlenecks, implementing continuous improvements, and increasing flexibility. Central aspects of the discussions included value adding, core processes, and flatter organization. Concrete elements of the planned modern organization at the studied companies were job rotation, autonomous teams, delegation of white collar work tasks to blue collar workers, cross-disciplinary cooperation, workplace learning, and larger integrated and connected work tasks for each worker. The companies tried to arrange the work organization and in some cases even rebuild the premises and the technology along the flow of the products (i.e., the production processes). By using different education and training activities, the companies wanted to induce change-readiness, holistic knowledge and understanding, cocreation, responsibility, empowerment, entrepreneurship, and a sense of company ownership in the individual worker.

This discourse of "the modern organization" is still very apparent in Sweden. In the follow-up study, the companies had new organizational change projects that were in part a continuation or even a reboot of the change project from ten to fifteen years earlier, but now the projects had names that included the word "lean" and were more clearly Lean Production projects. The projects included various permutations and combinations of the usual tools and elements of Lean, but also more organizational ideas like cross-functional process teams. In this way, the three companies' change projects were all typical examples of the renaissance and second wave of Lean (Björkman and Lundqvist 2013). Lean appears as the most enduring and thorough management concept from the 1990s. It is the dominant and taken for granted model for organizational design (Handel 2014) and has clearly moved from rhetoric to practice, resulting in real organizational changes in many Nordic companies (Sederblad 2013). Even in those cases where the modern organization is not actually implemented in its entirety, which is usually the case, it plays a role at the discourse level and therefore still influences the social constructions in organizations: how people view the organization, the profession, the work, and themselves as workers and, by extension, gender.

\section{Restoration and resistance}

During the 1990s through today, international management literature paints a very bright and optimistic picture of the future for companies (and their workers) if the companies implement the organizational models. Such a strategy, so the literature emphasizes, results in continuous improvements, better productivity and quality, survival on the global market, and at the same time better work environments and more developing and interesting jobs for the workers by getting rid of the classic Taylorism. We can also find arguments that the models will result in better innovation capability, safety, health, learning, or even gender equality. In the same spirit, all the companies in the initial study undertook their implementation projects in concert and positive cooperation with trade unions and with the joint aim to do good for both the company and its employees.

In spite of the high level of consensus, the diversity of optimistic perspectives, and the extensive dissemination of the ideas throughout industry, all the studied companies in the initial study ran into obstacles, resistance, diffuse disobedience, and even conflicts when trying to implement the modern organizational models during the mid-1990s. The 
organizations more or less reverted to previous forms despite the fact that this often was quite irrational and counterproductive from a productivity and economical perspective as well as from a work environmental perspective, a phenomenon I call "restoring the order"; the behaviors and organizational processes or mechanisms that strive to keep such a status quo or return to status quo I call "restoring responses" (Abrahamsson 2002). ${ }^{4}$

Some of the problems in the studied companies' change projects could be explained by the inadequate methods sometimes used by the companies but perhaps most from the fact that organizational structures and cultures often are conservative and difficult to change (Martin 2002). It is difficult to manage and control planned changes and unintended changes often are the result. Clearly, some of the restoring responses maintained and even strengthened internal organizational territories, power structures, and wage and status differences, formal as well as informal. From this perspective, the restoring responses can be analyzed as rational resistance (Linstead et al. 2014).

There are also explanations connected to paradoxes and contradictions imbedded in the modern organizational models. For example, the models often simultaneously promote integration and segregation, decentralization and centralization, as well as upskilling and deskilling (Johansson and Abrahamsson 2009)—giving different consequences and possibilities for different groups of employees. Furthermore, the organizational models are loose and represent incomplete ideas that have to be translated, interpreted, and adapted to the existing organization (e.g., Eriksson-Zetterquist 2009; Furusten 1999; Røvik 2003), which opens up for restoring responses, especially in strongly gender unequal organizations.

Moreover, despite the talk about a paradigm shift, these models very seldom attempt to change basic power and capitalist structures (nor any formal or informal gender systems). On the contrary, in some aspects they adapt and fit in very well with existing structures (Taylor 2006) and discourses (Kelan 2007), many of them clearly gendered (i.e., gender unequal). Therefore, some of the restoring responses may be resistance to uncomfortable gender inequality in the modern organizational models as well as in the existing work organization.

Some researchers have argued that many of the features of Taylorism remain in the modern organizational models, especially in Lean Production, which continues to result in the same types of work environmental problems (e.g., Berggren 1993; Johansson and Abrahamsson 2009; Thompson and Warhurst 1998). Literature reviews on Lean Production and workers health conclude that Lean Production often is connected with work task fragmentation and standardization, increased work intensification, and low levels of participation and empowerment (Hasle et al. 2012; Landsbergis et al. 1999; Toivanen and Landsbergis 2013; Westgaard and Winkel 2011). There are also problems such as "greedy organizations," more insecure and short-term appointments, and growing surveillance of the individual (Rasmussen 1999). Therefore, some of the resistance can be seen as healthy and creative (Newsome 2003), even if analyses of Lean used in the Nordic working life show less negative consequences on the working environment (Brännmark et al. 2012) and there are some examples of an "employee supportive lean" (Hasle 2014).

Nevertheless, taken together, these ambiguities and dynamics in modern organizational models encourage restoring processes as well as hinder the good parts of the models. If organizations want to achieve positive effects, the organizational models must first 
be implemented, a step that is not always easy to accomplish. So, although the modern organizational models or the implementation methods by no means are problem-free, many of the restoration responses can be seen as problematic and therefore important to analyze. The basic approach in this article on organizational change is that change happens all the time and it is difficult to control. Furthermore, unintended changes often are the result; as I will be discussing later, some of these changes are related to doing gender.

\section{Gender analyses of "the modern organization"}

Martin and Collinson (2002) noted that gender studies have neglected the conditions and consequences of the modern organizational models. This neglect, sadly, is still the case although there is some progress in this area. For example, as will be presented in more detail later, the initial work for this study has identified many gender-based restoring responses when companies implemented a modern organizational model. Similar results are also found in many other studies from other European countries. For example, Kahn (1999) showed that organizational changes in the daily practices and routines aimed at functional flexibility at two British hospitals were met with resistancemostly by male workers. The resistance manifested in concrete as well as symbolic ways as the organizational changes would have made the men perform "women's work," a change that the men were unable to accept. Some of the male workers even left work rather than accepting the new work tasks. In addition, the union passively supported this resistance. Khan concluded that the change projects created more continuity than change in the organizations' gender patterns. Drawing on results from a study of Japanese transplants in the UK, Taylor (2006) argued that Lean Production uses existing social patterns and does not change the unequal gendered work organization and employment forms.

Newsome (2003) described how the introduction of a modern organization in three industrial organizations in the UK intensified prevailing gendered divisions of labor and disproportionately affected women workers. Angelis et al. (forthcoming) made similar conclusions in their large-scale empirical study of gender differences in job stress responses to Lean Production in UK industrial assembly companies. The study showed that the effects of favorable job stress of Lean Production implementation were limited primarily to the male workers, while the unfavorable effects tended to have a greater influence on the women workers. In addition, Lean Production forced supervisors to assign only physically strong men to certain demanding job tasks instead of making improvements in the work environment. As a result, these supervisors created ergonomic difficulties for the men and probably also for the women because it limited the possibilities for job rotation. Carter et al. (2013), in a study of ill-health in the UK public sector, found that organizations based on Lean Production contributed most to employees' illhealth complaints and this was the case for women more than men.

Losonci et al. (2011) described a Hungarian case where the implementation of Lean Production created more gender-homogeneous jobs and more pronounced gender segregation within the organization. In a male-dominated welding unit, the proportion of women decreased from $21 \%$ to $7 \%$ during the Lean Production implementation. That is, the "male jobs" actually became even more "male." The study also showed that 
women and men were treated differently during the implementation process and that the better parts of Lean (e.g., participation and empowerment) were implemented at the male-dominated unit and the "women's unit" was given the more problematic parts of Lean (e.g., job intensification and standardization).

Zanoni (2011) found that in a Belgian industrial company women were discursively constructed as unable and unwilling to perform as expected within the factory's Lean Production system. The women were portrayed as lacking necessary skills, flexibility, and physical characteristics and, moreover, they were described as taking advantage of their "differences" to escape heavy jobs or work on the production line. Zanoni concluded these attitudes were combined with processes of slimming the organization by outsourcing lower value-added jobs and firing people, mostly women, working in those parts of the production. Drawing on results from their study on Finnish modern leadership discourse, Katila and Eriksson (2010) described how male CEOs were portrayed as possessing the new leadership competences, such as employee empowerment, interpersonal relations, and emotional skills, whereas women CEOs were portrayed as old-fashioned and possessing a less valued leadership style. In a similar analysis, Kelan (2007) concluded that although contemporary management literature presents women as the new ideal worker, a seemingly progressive view, this literature maintains traditional notions of femininity and gender inequality as free choices for women.

Market feminism is based on the popular idea that gender equality favors growth and innovation and that gender equality can be driven by market forces. The problem, of course, is that "the invisible hand of the market" may only demand a limited form of "gender equality" - a white, patriarchal, and heterosexual model with two different and complementary sexes. Even if it can be a fruitful change tool, Kantola and Squires (2012) and Petersson McIntyre (2014) argued hanging gender equality on concepts such as productivity and profitability may be problematic. Gender equality is not always direct nor does it always produce short-term profits for companies and organizations. That is, equality, justice, and democracy have values, motivations, and time horizons other than those determined by free market forces. Moreover, Acker (2011) reminded us that we should not underestimate the capitalist patriarchy or the power of class and status relations. Gender inequality in work organizations is perhaps in place because it is functional, effective, and profitable, at least in some aspects and for some groups.

\section{Organizational changes-an important site for doing gender}

The basic conception of gender used in this article is that gender and its meanings and consequences are socially constructed (cf., West and Zimmerman 1987, 2009) and that work organizations are an especially potent site for doing gender (Ely and Meyerson 2010). This conception of gender is sometimes described as inherent gendering—structural, cultural, and discursive—of work organizations (e.g., Acker 1990, 2006, 2011; Collinson 2005; Martin 2006; Meyerson and Kolb 2000), technology, employment forms, and work environments. In this article, the theoretical framework focuses on issues of fluidity, ambiguities, paradoxes, and gradual relevance of gender (e.g., Deutsch 2007; Eriksson-Zetterquist 2008; Kvande 2007 Nentwich and Kelan 2007). As Deutsch (2007) argued, it is important to study the variations and degrees of 
gender inequality and gender equality. Organizational gender patterns-gendered structures, symbols, practices, and identities-vary in their extent, importance, and strength within and between different organizations and are found in a multitude of local expressions that vary according to hierarchy, class, regional context, and other social aspects (e.g., Acker 2006, Kvande 2007; Martin 2002, 2006; Thurén 2000). These varieties can interact with individuals as well as organizations in many ways (Kvande and Rasmussen 1995). In this article, I use these theories as a basis for my exploration on how different organizational gender patterns can function differently during planned organizational change (such as companies' projects aiming to implement a "modern organization") and during the restoration processes, resulting in many ways of doing gender in the organizations.

\section{Analyzing simultaneous stability and change}

Doing gender approaches have often been used, including in my initial study (Abrahamsson 2002), to describe and analyze how existing gendered patterns and relations are maintained and how differences between men and women continue to be created despite structural, organizational, and institutional changes that open up for changes in gender patterns. In the same way as radical structural perspectives, doing gender approaches have therefore been criticized for becoming a theory of gender persistence and the inevitability of gender inequality (Deutsch 2007; Martin 2011; Nentwich and Kelan 2007). Within the research field of gender and organization, this tendency is not surprising: when it comes to the most common types of jobs and occupations, stable gender stereotypes and strongly entrenched collective gender identities remain and are perhaps even more stable than those that exist in other spheres of a person's everyday life. There is also a risk of treating working life and work organizations as something natural and stable, as a background or coulisse to where gender is done. Such treatment, as Ashcraft (2004) noted, results in a loose grasp on power, structures, and material aspects, all conditions that also are changeable and part of the doings of gender.

Changes, mostly unplanned, in both gender and organizations occur constantly and operate on multiple levels. To understand this, we need to theorize and research the relations between the levels. A challenge for gender research is to see doing gender as both stability and change and to bridge from the micro-level to the meso- and macro-levels and vice versa. In this article, I try to grasp these complex relations by drawing inspiration from scholars such as Acker (1990, 2006), Gunnarsson et al. (2003), Kvande (2007, 2003), Ely and Meyerson (2000), and Meyerson and Kolb (2000) among others and build my analyses on a model with four gendered and gendering processes-structures, symbols, interactions, and identities-that form an interactive and dynamic system; I call this "the quadrangle model."

Such a model can be used to analyze cases where the processes are integrated and follow each other. This often illuminates how gender inequality persists, which also is Acker's important contribution, but it also allows for analyses of asymmetrical changes and simultaneous occurrences. In each process, there is both interplay and asymmetries between the individual, organization, and society, between the micro- and macrolevels, between practices and practicing, and between external and internal processes. Naturally, these interactions create empirical as well as analytical difficulties, but as 
Kvande (2007) argued, such an approach makes it possible to discuss how gender can be created in different ways in the various processes resulting in asymmetrical changes where gender can take on varying degrees of importance within each process in the same organization. Changes in one process do not need to entail corresponding changes in other processes. In some cases, the processes can function as (perhaps temporarily) counterreactions and backlashes. For example, the more gender equality in the form of gender integration and gender tone down at the structural and formal levels, the more important gender inequality (i.e., gender segregation and gender stereotypes) will be at the symbolic level (Deutsch 2007; Hirdman 2001). In this article, these theories make it possible to illuminate and explain variations, paradoxes, and simultaneous negative and positive changes.

Deutsch (2007) and Lorber (2000) argued that there is a need to further explore how the different levels or processes work together to produce positive change-less gender inequality. For example, analyses of when and how structural changes, such as more gender integration and less gender differences in working life, create possibilities for changes at the interactional and symbolical levels of the doings of gender. In addition, we could look for how positive changes at the symbolic level of gender drive similar changes at the structural level of gender. Similarly, we need to study whether and how changes at the micro-interactional level, such as resistance against gendered interactions, drive changes at the structural and symbolic levels. Deutsch (2007) proposed using the phrase "undoing gender" for processes that reduce gender differences and Lorber (2000) concluded that to create gender equality requires thinking about the possibilities of a nongendered social order. Even if these ideas are not new, it is actually a growing field within gender research; however, it is easier said than done. Not doing gender is not the same as undoing gender. In situations where gender is rendered irrelevant, other hierarchical systems can take over. However, according to Martin (2011), empirical approaches are needed that can analyze degendering practices in organizations with high degrees of gender equality. What would organizations with less gender inequality or even gender equality look like? And more important: How is gender done or perhaps undone in these types of organizations? Ely and Meyerson (2010) provided some empirical contributions to the understanding of undoing gender in work organizations. They described how organizations could disrupt the gender status quo as they loosen the workplace culture's grip on men and masculinity. Ely and Meyerson identified three components that can equip men with the requisite skills and perspectives to undo gender: collectivistic goals, learning orientations toward work, and the alignment of definitions of competence with task requirements rather than with idealized images of masculinity. Ely and Meyerson did not directly connect these components with "the modern organization," but I see interesting similarities with some parts of "the modern organization." In this article, the theories on undoing gender and degendering function as inspiration to look for gender equality.

\section{Results}

The presentation of the material is organized as follows: for each of the three cases (male-homogeneous, gender-segregated, and gender-mixed), I present the findings of the initial visits (mid-1990s) and the follow-up (the mid-2000s). 


\section{The male-homogeneous organization}

\section{The initial visit: minor organizational changes and indirect restoring responses}

The Kraftliner Factory in northern Sweden was a typical large male-homogeneous industrial work organization where the women were clearly the minority. In 1994, the gender balance among production workers was 3\% women and 97\% men. Although the company made no major efforts to change this, there was some hope that the investments in automation and new ergonomic workplace design would make it easier to recruit more women, but the talk about gender equality was very clearly just talk and mostly focused on the difficulties of persuading women to apply for jobs at the factory. In the 1990s, their approach to gender equality was mainly built on a combination of liberal individualistic and sociobiologic ideas of gender. They arranged lectures and seminars with titles such as "Creative Differences" and "Female and Male Leadership" for both managers and workers. This approach was also evident at the Napkin Factory, the Opto-fiber Factory, and in the society at large.

Kraftliner Factory's production organization was characterized by a homogeneous workplace culture in which working-class masculinity was important, an attitude that was both openly discussed and hidden. Although this type of masculinity was sometimes seen as obstructively conservative, it enjoyed certain support in the local community and the participating men seemed to experience it as an enjoyable and undemanding form of social interaction. The working-class masculinity was probably a way to deal with feelings of subordination and inferiority (cf., Collinson 1992; Willis 1977). Although the women workers also thrived on the job and did not regret their career choice at all, it was clear that they suffered many of the "minority effects" that Kanter (1977) described. They were usually the only women in their work teams and had no contact with each other. Most of the women were skilled workers with 15-20 years of experience in industrial production. All the women had been subjected to comments about "being in the wrong place," comments that suggested that women did not belong on the factory floor and that the job was too demanding or too technical for them. It was also very easy to recognize the common individual strategies used in dealing with such minority effectsincluding being a "mum" or "one of the guys" (cf., Kanter 1977; Kvande and Rasmussen 1995; Lindgren 1985; Powell et al. 2009). Moreover, semipornographic calendars hung in the control room, break room, and production offices, signaling that women were (and should be) present only in the periphery (cf., Höök 2001).

The gender pattern also had a structural dimension-both horizontally and vertically and formally and informally. One woman worker described this as a "status staircase" of which the higher levels were inaccessible to her. Although movements between levels or workplaces in general were rare, male workers could expect to move from the "dry end" to the "wet end" of the paper production machine, a clear advancement in their careers. The women workers seemed to both start and remain at the "dry end," the lowest step on the staircase.

The organizational change project I followed in the mid-1990s at the Kraftliner Factory focused on the implementation of job rotation, workplace learning, empowerment, dehierarchization, and cross-functional cooperation. When the new organization was implemented, each worker was educated in the new attitudes and principles: willingness to change, teamwork, and management by objectives. Some parts of the cross-functional 
cooperation (or at least the dialogue) seemed possible to accomplish, at least in the long term. However, eventually the change processes came to a halt. One explanation could be that much of the old organization's "status staircase" was built into the new organization, as were the old workplace cultures and gender patterns. For example, only men were appointed to the project groups and to the new positions that were created to fit the idea of the new organization (cf., Katila and Eriksson 2010; Newsome 2003; Zanoni 2011). In summary, because the Kraftliner Factory's organizational changes were not very profound, they were not met by many direct restoration responses, but rather by more indirect restoring mechanisms, such as passive disobedience.

\section{Ten years later: new perspectives on gender equality?}

When I contacted the Kraftliner Factory more than a decade later to ask if I could come there to do a follow-up study, the immediate and proud reply was " $\mathrm{t}]$ here are many more women workers now." They also told me that the company had recently worked hard on gender equality by recruiting many women to a trainee program. This seemed like a very positive development, but as I discovered later, the proportion of women in production jobs had only increased from just over $3 \%$ to $4 \%$. However, it is interesting to note that the company seemed to believe that there were many more women workers than ten years earlier and was truly proud of that "fact." This perhaps indicates that even a small change can feel as if it is a huge leap if it challenges a strong existing (unequal) gender order. I have seen the same tendencies in other male-dominated industries. Over the years, male-dominated industries have run many campaigns to recruit women, but without any major gains. The inertia in the male-homogeneous work organization seems hard to change (cf., Abrahamsson 2006; Abrahamsson and Somerville 2007). When I asked why there was such slow development, I was given the explanation that the women did not apply for the jobs and that work was too physically demanding for women. I interpret these explanations as a continuing desire to at least partly place the problem of gender inequality outside the realm of the company and outside the realm of personal responsibility. I found it interesting that the classic excuse of "heavy jobs" was still used in spite of the fact that the clear majority of production work involved monitoring and operating remote-controlled processes while sitting in front of a computer screen in a control room. The technological development and improvement in working conditions did not seem to have been able to alter the view that the work is too demanding for women.

Despite the perpetuation of this traditional situation, I did see some positive changes. There was no doubt that the Kraftliner Factory, at least officially, more clearly than before wanted more women employees. In various official forums such as newspaper interviews, the site manager was quoted as saying he wanted to recruit more women. The factory's gender equality plan said that a better gender balance was expected to lead to a more pleasant work environment, more efficient work, and a better reputation in the community. The most evident of the positive changes was the complete disappearance of semipornographic calendars from the workplaces. Another clear change I observed was a shift in perspective from sociobiologic ideas about gender to structural and even social-constructionist perspectives on gender. The top management had organized a series of lectures on gender as social constructions and gender equality as organizational 
changes. They even participated in a research project that applied gender theory. The top management seemed to have concluded that part of their gender inequality problems might have rested in the organization itself. In addition, the management seemed to desire a modern and radical approach to gender equality; at least their rhetoric reflected this view. One interpretation of their somewhat too optimistic description of the number of women workers can be that it was a way of describing these cultural and symbolic changes, which can be difficult to put in words.

When it came to the organizational change project, I was first told that nothing had changed and it seemed that the organizational change process really had come to a stop and never recovered. But the more I talked with people at the plant, the more I understood that the situation had not been totally static or negative. The ideas taken from the modern organization models from the 1990s-that is, multiskilled and autonomous teams-were included in an ongoing Lean Production project. The women workers were part of these teams (as they were ten years earlier), and they, once again, expressed positive attitudes toward the new work organization.

\section{The gender-segregated organization}

\section{The initial visit: many direct, gender-based restoration responses}

The Napkin Factory, part of a medium-sized pulp and paper company in central Sweden, had a production organization with an equal number of women and men. In relation to the rest of the pulp and paper industry, this figure represents a very high percentage of women workers. What mostly characterized the Napkin Factory was its clearly gendersegregated production organization: women were mainly machine operators (working with the roller machines) and men serviced the machines (working with daily machine service and adjustments). In this type of organization, many work organization boundaries, such as those between divisions and work tasks, have links to gender (cf., Taylor 2006). At the Napkin factory, as in many other organizations, this resulted in men having better work conditions and more options and in men's work being accredited a higher status and better pay. When I conducted my interviews in 1994, there was also a lot of talk about differences between women and men and femininity and masculinity, some of which was casual talk and some of which served as explanations for their organizational and workplace problems. When it came to gender equality, the management expressed that its aim was to improve the inferior work environment and lower status of "women's work." However, the gender equality issue that was most often mentioned was the difficulty in recruiting men and it was openly stated that men were prioritized during recruitment. In many ways, gender was quite a significant issue within the organization.

The organizational change project included the implementation of multifunctional and autonomous teams and job rotation between production work and daily machine service. The purpose was to create flexibility, accessibility, and faster daily service to reduce the duration of production stoppages and idle time for the machines. Servicing machines would also create an opportunity for machine operators, the vast majority of whom were women. This opportunity would create greater variety in the women's jobs thereby creating a better work environment for them. This undoubtedly contributed to the high level of engagement in the project among the women workers. 
It was intended that the men (repairers) and the women (machine operators) would be part of the same work team and the same job rotation, that is, each worker would both operate the machines and perform daily service on the machines. However, these ideas proved to be impossible to implement, at least in the short run, because the male workers protested (cf., Kahn 1999). The male workers did not want to join job rotations or teams that included women. Some of them openly said that they did not want to work at a "woman's machine"; it was seen as degrading work. Moreover, the majority of the repairers refused to assist in the training in daily service of the machine operators. Several of the men chose to move out of the Napkin factory to take up work in maledominated areas of the company, which presumably offered a more secure male gender marking. Connell (1995) would probably describe this as the men's fear of being seen as unmanly. As a result of this open resistance, the gender segregation in the organization became even more pronounced (cf., Losonci et al. 2011).

Another part of the problem was that the women were not thought to possess any technical knowledge in spite of the fact that they had 10-20 years of experience in technical industrial work. When performing the daily service job, as some of the women started to do after all, they were subject to jeering from the men. In addition, the majority of the women did not consider themselves sufficiently technically minded for the job and did not want to expose themselves to the risk of harassment. These conditions illustrate the complex link between the social constructions of masculinity and the social constructions of certain technology (cf., Mellström, 2004).

Management's solution to this problem was that men were prioritized when recruiting new personnel. Management believed it would be easier for them to learn the adjustments to the machines and to begin to perform daily machine service. Clearly, management openly sided with the men. There were many examples of alliances between male workers and male managers. It is true that the idea of integrating maintenance and production work came from management and it was also management that promoted the organizational changes, despite protests, but when it came down to it, management was not prepared to force the men to perform "women's work." Instead, the men were offered more time and other work duties. Interestingly, the women also felt that the men had been treated badly and did not want the men to be forced to perform "women's work."

The other part of the organizational project-to attempt to introduce autonomous groups-resulted in responses with a similar pattern. Supervisor positions were eliminated and in each team the role of coordinator was rotated among the team members. Initially, it seemed that the company had succeeded in creating more varied and interesting work for its employees, but a range of problems occurred here also. The production manager called this "The Women Problem." The women themselves saw the problems as being due to a lack of formal authority and related that the men did not want to take orders from women foremen and instead chose to go behind their backs and talk directly to the male production manager (cf., Kahn 1999). Management's solution to this problem was to reintroduce the supervisor position, which, as it happened, was given to men (although not the same individuals as before).

The change project at the Napkin Factory was more comprehensive and radical than what was implemented at the male-dominated Kraftliner Factory (cf., Angelis et al. fortcoming). In the initial study, the male-dominated workplaces seemed generally to be treated more gently, whereas the gender-segregated organizations used drastic methods 
to a greater extent, including compulsion, when different parts of the new organization were implemented, perhaps for the expressed purpose of trying to manage the difficult point of entry (the gender segregation). However, there was resistance, even open conflicts, and different types of restoration mechanisms eventually resulted in the organization looking very much like the original form, a return to the status quo. In some cases, this happened even before the new organization had begun to function. As described earlier, many of the restoration responses were gender-based and resulted in restoring gender segregation and gender hierarchy.

\section{Ten years later: after all, changes and tendencies of a "gender tone down"}

Returning to the Napkin Factory after ten years, I first found that little had changed. The number of employees was approximately the same as ten years earlier, and the gender distribution looked the same in spite of the fact that there had been a number of rises and falls over the years. It is noteworthy that the Napkin Factory showed no tendency to reduce the proportion of women workers $(50 \%)$ even when the labor market within the industry was tough or when the company invested in new technology.

As explained earlier, attempts to introduce multiskilled and autonomous teams at the Napkin Factory came to a complete halt due to direct opposition and open conflicts, and the company chose to make a wholesale return to the old organizational structure. In spite of the fact that more than ten years had passed, the old project was still a sensitive issue and was deemed a major failure. One of the managers interviewed said that they had not dared to tamper with the organization again since that time. The manager noted that the situation remained unchanged with clearly segregated machine operators and repairers.

However, the situation at this company was neither as fixed nor as negative as they said nor as it initially appeared. The company had recently embarked upon a new change project inspired by Lean Production, which was very similar to the old project. So far the production staff had been divided into autonomous teams with a coordinator's role assigned within each. Of these 12 team coordinators, 10 were women. From a gender equality perspective, this is interesting since the percentage of women normally decreases as one moves up the hierarchy.

There were also other positive changes. Because there had been a number of market fluctuations during the intervening years that forced layoffs, reemployments, and the shifting of personnel, there had been a certain degree of movement between positions and divisions. This had resulted in a number of male repairers who now had experience as machine operators and many of the women machine operators had been given the chance to try working as repairers. A foreman who I interviewed explained that this was a natural development in a lean and flexible organization. So, the machine operators now performed some parts of the daily service on their own machines. This applied to the women machine operators as well in spite of the fact that previous attempts to introduce this idea were met with complete failure. Now there were even three women who worked as repairers, which would have been impossible ten years earlier. Even the talk about "women's work" seemed to have quieted down. One of the staff members said, "[n]obody is surprised to see a guy working at one of the machines any more." 
All in all, the follow-up study at the Napkin Factory shows that relatively large sections of what had failed in its implementation the first time had been rather successfully implemented now, although after a long delay. Additionally, a number of unexpected positive effects had occurred in relation to gender equality. It should be pointed out, however, that these positive changes, in spite of everything, were quite marginal when viewed against the backdrop of the bigger picture. It continued to be difficult to recruit men to the Napkin Factory and above all to positions as machine operators and the basic division between "men's work" and "women's work” remained.

\section{The gender-mixed organization}

\section{The initial visit: gender equality as a prerequisite for sustainable development}

The company with the highest degree of gender mixing-that is, a lack of gender marking and gender segregation within the production organization-was The Opto-fiber Factory in northern Sweden. On the whole, the company was no more gender-equal than any other. Indeed, there existed a gender pattern with male managers and women administrators and cleaners. Production, however, was organized into workplaces where women and men worked on similar tasks in the same divisions. Even here there existed certain work teams in which only women worked as well as certain positions that were held almost exclusively by men (technicians, repairers, and supervisors), but on the whole gender segregation and gender marking were not particularly pronounced or visible, at least among the production workers. There were many work duties that were not subject to gender marking and segregation. Men and women employed in production were paid the same wage, thanks largely to the fact that the company paid a fixed monthly wage. No gendered conflicts were evident. Compared with the other studied companies, gender-femininity and masculinity—did not appear to be an especially important issue within the organization. One possible explanation for the absence of at least some kind of gender segregation was that the Opto-fiber Factory operated in an industry with rapid technological development and complex competition. To keep pace, companies needed to switch product and production practices quickly. A fluid situation such as this may make it more difficult for rigid organizational structures based on gender or other informal barriers to gain a foothold.

This situation also seemed to have a positive effect on the change project. There were few visible signs of gender-based restoring responses and the planned implementation process went on quite smoothly. Opto-fiber's organizational change project can even be described as rather successful, compared to the Napkin Factory and the Kraftliner Factory. In 1994 and 1995, Opto-fiber successfully introduced a learning organization with multifunctional autonomous work teams, coordinators, and job rotation. This success may have been the result of the lack of fixed attitudes and positions with respect to gender-based blockings thanks to the gender-mixed organization.

\section{Ten years later: new forms of gender segregation and gender marking}

The earlier successful change project at the Opto-fiber Factory seemed to have remained intact ten years later. The learning organization and the autonomous, multifunctional 
groups introduced in the mid-1990s still functioned as intended. The teams had retained their administrative work tasks (e.g., staffing schedules and production planning) that had been delegated to them, and they had an overview of the entire production chainfrom order to delivery. What was new was that the company had just begun implementing Lean Production in the production organization.

The company's pamphlets and newsletters described the company as an organization built on gender equality where women and men received the same wages and worked side-by-side throughout the production organization. The company's literature also mentioned gender equality as a prerequisite for achieving flexibility and organizational change. These kinds of ideas about gender equality did not exist-at least they were not explicitly stated-during the first round of interviews ten years earlier. Perhaps this new perspective was the result of the changed discourse on gender equality in Sweden today and perhaps they may have been influenced by my research. It was clear, however, that the gender-mixed organization remained and that it was mostly women who took on the special assignments in the work teams.

On the other hand, other trends can be viewed in a less positive light with regard to gender equality. For example, the percentage of women employed by the company had fallen. Because the company had switched to producing more services (technology based) and the actual production of goods had decreased, the number of production workers had also decreased. The majority of women worked in the production division whereas the majority of the men worked primarily with services. In addition, the proportion of male workers within the production staff had increased slightly. One reason given for this was that the qualifications required for employment had been changed to include even more stringent requirements for technical skills. Very few of the women workers possessed these qualifications. Instead of relying on their learning organization and education of the women, the company chose to provide technical training to men in other divisions or to recruit qualified male workers externally. This strategy actually decreased the number of women production workers, resulting in newly constructed gender segregation within the production organization. In the long run, this situation may turn the company into a traditional male-dominated industrial company.

\section{Discussion}

The results from the initial study showed that the implementation of "a modern organizational model" had different processes and effects when it was implemented in different types of gendered production organizations. In short, the greater significance gender had in the organization, the more restoring responses during the organizational change project. The follow-up visits at the three companies showed that the different types of gendered organizations still resulted in different types of development, but in a different way. For example, there were indications of positive changes when it came to the organizations' internal gender patterns, even at the company that in the initial study had experienced many gender-based restoring responses. It seemed at least that the implementation of "a modern organizational model" (e.g., Lean Production) eventually occurred together with gender equality, a situation that perhaps could pave the way for more gender equality in working life. However, taken together, the results showed 
a complex picture of asymmetrical and contradictory changes when it comes to gender and work organization. Below I will discuss this in terms of inertia, regendering, and degendering.

\section{Inertia-restoration of both organizational structure and old gender patterns}

In the initial study, several examples of restorations of both organizational structure and gender patterns were evident. Such processes could be seen at the Kraftliner Factory (male-homogeneous organization), but it was most evident at the Napkin Factory (gender-segregated organization with significant gender segregation, gender marking, and gender stereotyping in the production organization). Here the integration, dehierarchization, and individualization aspects of the modern organization clearly challenged the local gender order based on segregation, hierarchization, and stereotypes. This challenge was met with open opposition and direct restoration responses (cf., Kahn 1999). Eventually, the organizational change projects came to a halt. Especially at the Napkin Factory (the gender-segregated organization), many of the restoration responses had clear links to the existing gender segregation in the organization and above all to the notions about "men's work" and "women's work." This created gender-based restoration responses that took place during the company's organizational change project. It was clear that the intended organizational changes-with autonomous work teams and job rotation-were not able to overcome stereotypical gender segregation and gender marking. The company's change methods and the planned new organizational structure instead followed the prevailing unequal gender order (cf., Acker 2006; Angelis et al. 2011; Losconi et al. 2011; Newsome 2003; Taylor 2006).

One part of the problem with the restoring responses was that they had clear negative effects for the women workers since the new planned organization probably would have meant better work conditions for them. Another part was that they resulted in a direct survival of gender segregation and hierarchy (i.e., restoring the unequal gender order). The quadrangle model (structures, symbols, interactions, and identities) reveals how all the processes worked in the same way, following each other and resulting in many examples of how gender inequality was restored (cf., Acker 2006). A third part of the problems was that, in many cases, these processes resulted in restoring other aspects of the organization's old structures, which were often the very structures that the companies had wished to change. These unintended consequences indicate that an organization built on gender inequality (i.e., gendered segregation, hierarchy, and stereotypes) can create backlashes for companies' implementation of a modern organizational model and by that result in an organization that risks lagging behind technically and organizationally (Abrahamsson and Johansson 2006). In the same way, Meyerson and Kolb (2000) noted that the same assumptions and practices that form gender inequality also undermine organizational effectiveness. One conclusion from the initial study was that the unequal organization of internal gender patterns (e.g., gender-based hierarchies and divisions, gender stereotypes, and gender marking of competences, tasks, and workplaces) hindered the industrial companies' abilities to create positive organizational changes, work environment improvements, learning, flexibility, and innovation-and especially the companies' ability to establish a "modern organization." 


\section{Regendering-old and new unequal gender patterns}

It was also clear that the organizational changes could be partially implemented at the same time as the unequal gendered organization was restored and remained, even if it took on a slightly different form. The results show at least two different variants of regendering. The first one was a "copy-paste" of the unequal gender order. The organizations changed slowly in response to the new organizational model, but the existing unequal gender segregation and gender marking remained stable (cf., Angelis et al. 2011; Losonci et al. 2011; Newsome 2003; Taylor 2006). This outcome was visible in the initial study at the Kraftliner Factory, the male-homogeneous organization. The structural organization of gender and the symbolic gender marking of work tasks followed into the new organization, at least as a start. In the initial study, it seemed as though the sociobiologic mindset of the 1990s (the belief of natural differences between women and men) together with the related traditional gender stereotyping of work tasks worked as a calming or subduing factor within the organizations. Inspired by Hirdman (2001), I use the quadrangle model to discuss the sociobiologic mindset as a counterreaction to the demands for gender equality that could be found in the theoretical forms of the modern management models. We can see how gender was created in different ways in the structural/formal processes and the symbolic/informal processes (Kvande 2007). At the follow-up visit to the Opto-fiber Factory, the gender-mixed organization, new structural gender segregation was emerging. It seemed as if the gender unequal symbolic processes were strong and affected the structures. The organization was slowly changing from a kind of genderequal organization to an organization based on something similar to traditional gender inequality. These pessimistic results indicate that gender equality can be temporary.

The second variant of regendering was a "new design" of the unequal gender order. In some aspects, the organizational projects addressed such major changes-structural and symbolical-that the projects actually had a major impact on gender in the long run. Therefore, it proved difficult to preserve the old unequal gender order; there seemed to be a "need" for a new type of (unequal) gender order. In the quadrangle model, this trend can be seen as the result of structural changes pushing forward symbolic changes in the ways of doing gender in the organizations (Kvande 2007). This push could also be seen in modifications of the content of masculinity and femininity in relation to the new competence demands (cf., Katila and Eriksson 2010; Zanoni 2011), a result of the fluidity and socially constructed nature of both competence and gender. I saw a hint of this in the follow-up at the Opto-fiber Factory, the gender-mixed organization, especially when it came to the stronger emphasis on technological competence and the connections to men and masculinity and in the emerging new competence demands (e.g., social competence, which men were expected to have). It seemed that when a particular competence became important, it turned "male" (Abrahamsson 2003). It is perhaps true that it was possible to implement the new model of work organization "thanks" to these dynamics in masculinities and femininities. The results show that an unequal gender order reappeared in new variants-with new types of gender segregation, new gender marking of skills and work tasks, and new ideas on "natural" gender differences-while maintaining a higher valuation for men and things considered masculine. Here, a glimpse of an explanation for the continued existence of the gender-segregated working life in Sweden is evident: gender inequality remained in spite of active attempts to break up organizational patterns and structures. 


\section{But also degendering-small steps toward gender equality}

Inspired by Martin (2011), Deutsch (2007), and Lorber (2000), I interpret the results from the initial study in a positive way; for example, the company that was most successful with its organizational change project was the one with a gender-mixed production organization, the Opto-fiber Factory. It was also clear that the results of the follow-up study painted a more positive picture of the situation at the Kraftliner Factory, the male-homogeneous organization, and the Napkin Factory, the gender-segregated organization, compared with the results of my initial study. These positive results included new organizational forms and at the same time new, more gender-equal organizations and practices (cf., Meyerson and Kolb 2000).

In my initial study, the organizational change attempts were not met exclusively by restoration responses. Some real and concrete changes were achieved. Some form of modern organization gained a gradual foothold even if it happened only slowly and in quite small increments. I described this progression as "two steps forward, one step back." In the follow-up study, it became clear that the companies had taken further steps forward toward a modern organization. They had implemented part of what they were just talking about ten years earlier even if they were, to some degree, unaware of their own progress. This was most evident at the Napkin Factory, the gender-segregated organization. One conclusion from this is that restoration responses and problems connected to the implementation of a new organizational model can be interpreted as a temporary or transitional condition (in this case I choose to see ten years as temporary although it actually is quite a long time). The companies slowly but surely began to reflect "the modern organization."

Because the modern organizational models are based on flexibility and integration, they can result, at least in their theoretical or ideal forms, in measures that combine and mix functions and employees in the organizational structure, and this would also involve attempts to mix women's and men's work and mix male and women workers. Using the quadrangle model, I found that the structural changes pushed forward changes in the symbolic processes, but this time producing positive change. The implementation of such organizational strategies would (in theory) make it difficult to keep gender segregation and stereotypes in the organizational structure and in the workplace culture, symbols, and behaviors. A continuous implementation of new technology at industrial workplaces, resulting in new types of work tasks, new competence demands, more safety, and a better physical work environment, would (in theory) challenge many older forms of gender stereotypes and gender inequality. The new organizational models at the studied companies also included a focus on workplace learning, cooperation, collectivistic goals, and definition of competences based on task requirements, which are, according to Ely and Meyerson (2010), components of an organizational culture that can form a good base for undoing gender.

In the follow-up study, it was clear that the changes were more than merely attempting to mix women's and men's work and mix male and women workers; the companies showed signs of concrete changes toward more gender-mixed workplaces and perhaps also reduced stereotypical views about femininity and masculinity (cf., Martin 2011). The three studied companies- to a certain degree without speaking of gender equalityhad made some changes in the direction of a more gender-equal organization. This was especially the case at the Napkin Factory, the gender-segregated organization, where a 
new gender mix was evident. It was clear that gender segregation-both at the working life level and within the companies-was seen as problematic and as an impediment to growth for the modern organizational concept (cf., Meyerson and Kolb 2000). Although these changes were far from pervasive, they were nonetheless interesting and they gave some support for the idea of market feminism (cf., Kantola and Squires 2012; Petersson McIntyre 2014). One conclusion from the follow-up study is that structural changes in the organizations also pushed forward changes in gender patterns, at least on the structural level. My empirical material from the follow-up study is unfortunately too limited to be able to show whether the gender changes at the structural level created other gender changes at the relational and symbolical levels (cf., Deutsch 2007).

However, as Deutsch noted, it is probably just as likely that changes at the individual, relational, and symbolic levels drive changes at the structural level. The slow but positive changes at the studied companies in the follow-up study were probably also the result of the accumulation of a common body of knowledge on gender and gender equality interventions based on social constructionism and similar perspectives. The companies exhibited an acceptance of relatively advanced gender theories (social-constructionist) and even concrete application of such theories, or at the very least, a willingness to apply them. In their practical interventions, the companies seemed to have left behind sociobiology ideology and an externalization of the reasons for gender inequalities; instead, they had begun to approach the idea of gender from a liberal structuralism perspective and to a certain degree they demonstrated insight that it is possible to influence gender equality from within their own company. This change was most evident at the Kraftliner Factory, the male-homogeneous organization. As described earlier, in many contexts in Swedish working life today there exist a kind of gender equality in the formal structures and an open, positive discussion about gender equality in the mass media, in industry, and by other labor market stakeholders (Grönlund 2014; SOU 2014:30). As a result, more demands are being placed on both private individuals and employers about attitudes and behaviors to counter stereotypical ideas about women and men.

Taken together, these changes may lead to gender becoming less influential in working life at the structural, relational, as well as symbolic levels, a trend that can be seen as some small step toward a "gender tone down," resulting in gender-mixed or even ungendered work organizations, workplaces where gender does not matter (cf., Deutsch 2007; Lorber 2000; Martin 2011). However, whether or not the companies can now progress from rhetoric to practice remains to be seen.

\section{Concluding reflections}

In this article I not only revisit old "study objects" but also revisit my own conclusion that gender inequality persists and can fuel organizational restorations and hinder a company's strategic organizational development and improvements in the work environment, as well as movements toward gender equality (cf., Abrahamsson 2000). The material namely told a story of how the organizations had changed toward more gender equality, at least in some aspects, since my first contacts ten years earlier. In addition to these changes in gender pattern, other organizational changes were evident-for example, moving toward a "modern organization." Although these hopefully positive changes were somewhat marginal, it seemed as if my previous conclusions were too 
pessimistic: the restoring mechanisms embedded in the unequal gender order seemed to be less influential in the long run than I had initially thought. In conclusion, the material indicates that the studied companies, in some aspects, developed into less gendered production organizations while taking steps toward a modern organization. This gives some support to the idea that gender equality can, at least in part, be seen as a prerequisite or perhaps even a side effect of the modern organizational concepts. But most of all, these glimpses of gender equality, even if they were just glimpses, are interesting areas for future research on how gender is done in more gender-equal organizations.

In other aspects, however, it seemed that my old pessimistic conclusions remained valid. The material also showed familiar patterns of inertia and opposition to such organizational changes that could affect existing unequal gender patterns. There was no doubt that the companies' implementation of a new and modern organizational model challenged, as a secondary effect, many aspects of the local prevailing unequal gender order among other organizational relations, resulting in more restoring responses than necessary. Gender inequality has powerful restoring mechanisms. One conclusion is that the companies' strategic organizational changes (e.g., implementation of Lean Production and similar models) will probably not be enough to create gender equality in the long run. The changeable nature of gender constructions is a central, although perhaps somewhat inaccessible, restoration mechanism within the gender-segregated working life. This means that we cannot sit and wait for the modern management concepts to create gender equality. Then maybe it results in only glimpses of gender equality and when there are new fluctuations in the labor market or in management fashion there is a risk that gender inequality will be restored.

To conclude, the companies' planned organizational changes are situations where unequal gender patterns become highly visible and also situations where gender patterns can be restored or changed and strengthened or weakened. It depends on how we do. Ely and Meyerson (2010) argued that organizations can be important sites for undoing gender and I would like to add that organizational changes (e.g., industrial companies' implementation of a modern organizational model) could be sites for undoing gender. However, movements toward some form of gender-equal work organizations need support. Such support could include continued development of methods for how to use gender equality as a useful and natural tool in companies' organizational change and efficiency projects and to counteract restoring responses. But equally important, I would argue, are the continued development of critical gender analyses of modern organizational models, their implementation processes, and their effects.

\section{References}

Abrahamsson, L. (2000) Att àterställa ordningen. Könsmönster och förändring $i$ arbetsorganisationer [Restoring the order. Gender patterns and change in work organizations]. Umeå: Boréa Bokförlag.

Abrahamsson, L. (2002) 'Restoring the order: Gender segregation as an obstacle to organizational development', Applied Ergonomics, 33 (6): 549-557.

Abrahamsson, L. (2003) 'When it became important, it suddenly turned male', pp. 253-284. In Gunnarsson, E., et al. (eds) Where Have All the Structures Gone? Doing Gender in Organizations. Stockholm: Centrum för kvinnoforskning, Stockholms universitet. 
Abrahamsson, L. (2006) 'Exploring construction of gendered identities at work', pp. 105-121. In Billet, S., Fenwick, T. and Somerville, M. (eds) Work, Subjectivity and Learning. Understanding Learning through Working Life. Dordrecht: Springer.

Abrahamsson, L. (2009) Att återställa ordningen [Restoring the order]. Umeå: Borea.

Abrahamsson, L. and Gonäs, L. (eds) (2014) Jämställdhet $i$ arbetslivet_organisatoriska villkor och ramar [Gender equality in working life-organizational conditions and frames]. Delegationen för jämställdhet i arbetslivet. Stockholm. SOU 2014:30 (Official Swedish Government Report).

Abrahamsson, L. and Johansson, J. (2006) 'From grounded skills to sky qualifications-a study of workers creating and recreating qualifications, identity and gender when meeting changing technology in an underground iron ore mine in Sweden', Journal of Industrial Relations, 48 (5): 657-676.

Abrahamsson, L. and Johansson, J. (2013) 'One hundred years of inertia. An exposé of the concept of the psychosocial work environment in Swedish policy and research', Nordic Journal of Working Life Studies, 3 (1): 5-29.

Abrahamsson, L. and Sederblad, P. (2013) 'Avslutning' [Concluding remarks], pp. 317-325. In Sederblad, P. (ed). Lean i arbetslivet. Stockholm: Liber.

Abrahamsson, L. and Somerville, M. (2007) 'Changing storylines and masculine bodies in Australian coal mining organizations', Norma (Nordic Journal for Masculinity Studies), 2 (1): 52-69.

Acker, J. (1990) 'Hierarchies, jobs, bodies: a theory of gendered organization', Gender and Society, 4 (4): 139-158.

Acker, J. (2006) ‘Gender and organizations', pp. 177-195. In Salzman Chafetz, J. (ed). Handbook of the Sociology of Gender. New York: Springer.

Acker, J. (2011) 'Theorizing gender, race and class in organizations', pp. 65-81. In Jeanes, E. L., Knights, D. and Martin, P. Y. (eds) Handbook of Gender, Work and Organization. Chichester: Wiley.

Andersson, S. and Amundsdotter, E. (2010) 'Action-oriented gender research: at the intersection between practical equality work and gender research', Paper at the $6^{\text {th }}$ International Interdisciplinary Conference Gender, Work and Organization, Keele University, UK, June 21-23, 2010.

Angelis, J., Conti, R., Cooper, C. and Gill, C. (forthcoming) 'Gender and Lean Job Stress', Working Paper, University of Cambridge.

Ashcraft, K. L. (2004) 'Gender, discourse and organization: framing a shifting relationship', pp. 275-298. In Grant, D., Hardy, C., Oswick, C. and Putnam, L. (eds) Organizational Discourse. London: Sage.

Bailyn, L. (2011) 'Redesigning work for gender equity and workpersonal life integration', Community, Work and Family, 14 (1): 97-112.

Benschop, Y. and Verloo, M. (2011) 'Gender change, organizational change and gender equality strategies', pp. 277-290. In Jeanes, E. L., Knights, D. and Martin, P. Y. (eds) Handbook of Gender, Work and Organization. Chichester: Wiley.

Berggren, C. (1993) 'Lean production-the end of history?', Work, Employment and Society, 7: 163-188.

Björkman, T. and Lundqvist, K. (2013) 'Lean ur historiskt perspektiv' [Lean in a historical perspective], pp. 18-47. In Sederblad, P. (ed) Lean i arbetslivet. Stockholm: Liber.

Brännmark, M., Langstrand, J., Johansson, S., Halvarsson, A., Abrahamsson, L. and Winkel, J. (2012) 'Researching Lean: methodological implications of loose definitions', Quality Innovation Prosperity, 1 (16): 35-48.

Carter, B., Danford, A., Howcroft, D., Richardson, H., Smith, A. and Taylor, P. (2013) ‘Stressed out of my box: employee experience of lean working and occupational ill-health in clerical work in the UK public sector', Work, Employment and Society, 2(5): 747-767. 
Collinson, D. (1992) Managing the Shopfloor: Subjectivity, Masculinity and Workplace Culture. Berlin: Walter de Gruyter.

Collinson, D. (2005) 'Discussion of Thomas and Davies: refuting romanticism: the values of feminist perspectives for understanding resistance', Organization, 12: 741.

Connell, R. W. (1995) Masculinities. Berkeley: University of California Press.

Deutsch, F. M. (2007) 'Undoing gender', Gender and Society, 21 (1): 106-127.

Ely, R. J. and Meyerson, D. (2000) 'Theories of gender in organizations: a new approach to organizational analysis and change, Research in Organizational Behaviour, 22: 103-151.

Ely, R. J. and Meyerson, D. (2010) 'An organizational approach to undoing gender: the unlikely case of offshore oil platforms', Research in Organizational Behaviour, 20: 3-34.

Eriksson-Zetterquist, U. (2008) 'Gendered role modelling—a paradoxical construction process', Scandinavian Journal of Management, 24 (3): 259-270.

Eriksson-Zetterquist, U. (2009) Institutionell teori_idéer, moden, förändring, Malmö: Liber.

Franzén, C., Lärkeryd, P., Sjölander, S. and Borgström J. (2010) Det lönar sig, genusmedveten ledning och styrning i verkstadsindustri [It pays. Gender aware management in manufacturing industry]. Stockholm: Näringslivets Ledarskapsakademi.

Furusten, S. (1999) Popular Management Books. How They Are Made and What They Mean for the Organization. London: Routledge.

Grönlund, A. (ed) (2014) Glimtar av jämställdhet [Glimpses of gender equality]. Umeå: Borea.

Gunnarsson, E., Andersson, A., Vänje Rosell, A., Lehto, A. and Salminen-Karlsson, M. (eds) (2003) Where Have All the Structures Gone? Doing Gender in Organizations, Stockholm: Centrum för kvinnoforskning, Stockholms universitet.

Göransson, U. and Sundin, E. (eds) (2006) Vad hände sen? Långsiktiga effekter av jämställdhetssatsningar under 1980- och 1990-talen [What happened afterwards? Long-term effects from gender equality interventions of the 1980s and 1990s]. Stockholm: VINNOVA Rapport VR 2006:08.

Handel, M. J. (2014) 'Theories of lean management: an empirical evaluation', Social Science Research, 44: 86-102.

Hasle, P. (2014) 'Lean production—an evaluation of the possibilities for an employee supportive lean practice', Human Factors and Ergonomics in Manufacturing \& Service Industries, 24 (1): 40-53.

Hasle, P., Bojesen, A., Jensen, P. L. and Bramming, P. (2012) 'Lean and the working environment - a review of the literature', International Journal of Operations and Production Management, 32: 829-849.

Hirdman, Y. (2001) Genus—om det stabilas föränderliga former [Gender-On the Changeable Form of Stability]. Stockholm: Liber.

Höök, P. (2001) 'Management as uncontrollable sexuality', pp. 149-166. In Sjöstrand, S.-E., et al. (eds) Invisible Management: On the Social Construction of Leadership, London: Thompson Publishing.

Johansson, J. and Abrahamsson, L. (2009) 'The good work-a Swedish trade union vision in the shadow of lean production', Applied Ergonomics, 40 (4): 775-780.

Kahn, P. (1999) 'Gender and employment restructuring in British National Health Service manual work', Gender, Work and Organization, 6 (4): 202-212.

Kanter, R. Moss (1993/1977) Men and Women of the Corporation. New York: Basic Books.

Kantola, J. and Squires, J. (2012) 'From state feminism to market feminism', International Political Science Review, 33 (4): 382-400.

Karlsson, J. C. (2013) 'Perspectives on Nordic working life research', Nordic Journal of Working Life Studies, 3 (3): 1-7.

Katila, S. and Eriksson, P. (2010) 'Recreating gendered managerial hierarchies by shifting positions', Paper at the $6^{\text {th }}$ Gender, Work and Organization Conference, Keele University, June 21-23, 2010. 
Kelan, E. (2007) 'The discursive construction of gender in management literature', Journal of Business Ethics, 81: 427-445.

Korvajärvi, P. (2011) 'Practicing gender neutrality in organizations', pp. 231-244. In Jeanes, E. L., Knights, D. and Martin, P. Y. (eds) Handbook of Gender, Work and Organization. Chichester: Wiley.

Kvande, E. (2007) Doing Gender in Flexible Organizations. Fagbokforlag.

Kvande, E. and Rasmussen, B. (1995) Women's Careers in Static and Dynamic Organisations. Acta Sociologica (1995) 38: 115-130.

Landsbergis, P. A., Cahill, J. and Schnall, P. (1999) 'The impact of lean production and related new systems of work organization on worker health', Journal of Occupational Health Psychology, 4 (2): 108-130.

Linstead, S., Maréchal, G. and Griffin, R. W. (2014) 'Theorizing and researching the dark side of organization', Organizational Studies, 35(2): 165-188.

Lorber, J. (2000) 'Using gender to undo gender: a feminist degendering movement', Feminist Theory, 1: 79.

Losonci, D., Demeter, K. and Jenei, I. (2011) 'Factors influencing employee perceptions in lean transformations', International Journal of Production Economics, 131: $30-43$.

Löfström, Å. (ed) (2004) Den könsuppdelade arbetsmarknaden [The gender segregated labor market], SOU 2004:43 (Official Swedish Government Report).

Martin, J. (2002) Organizational Culture-Mapping the Terrain. Thousand Oaks: Sage.

Martin, J. (2011) 'Does gender inequality ever disappear?', pp. 213-230. In Jeanes, E. L., Knights, D. and Martin, P. Y. (eds) Handbook of Gender, Work and Organization. Chichester: Wiley.

Martin, P. Y. (2006) 'Practicing gender at work: further thoughts on reflexivity', Gender, Work and Organization, 13 (3): 254-276.

Martin, P. Y. and Collinson, D. (2002) 'Over the pond and across the water: developing the field of gendered organizations’, Gender, Work and Organization, 9: 244-265.

Mellström, U. (2004) 'Machines and masculine subjectivity, technology as an integral part of men's life experiences', in Men and Masculinities (eds) Faulkner, W. and Lohan, M. Special Issue: Masculinities and Technology, 6 (4): 368-383.

Meyerson, D. E. and Kolb, D. (2000) 'Moving out of the 'armchair': developing a framework to bridge the gap between feminist theory and practice', Organization, 7: 553.

Nentwich, J. C. (2006) 'Changing gender: the discursive construction of equal opportunities', Gender, Work and Organization, 13 (6): 499-521.

Nentwich, J. C. and Kelan, E. (2007) 'All said and done? Understanding doing gender and its discontents', Paper at the $5^{\text {th }}$ International Conference on Gender, Work and Organization, Keele University, Staffordshire, UK, June 27, 2007.

Newsome, K. (2003) 'The women can be moved to fill in the gaps: new production concepts, gender and suppliers', Gender, Work and Organization, 10: 320-341.

Petersson McIntyre, M. (2014) Jämställdhet på köpet?-Marknadsfeminism, innovation och normkritik [Gender equality in the bargain?-Market feminism, innovation and norm critics]. VINNOVA Rapport VR 2014:02.

Rasmussen, B. (1999) Dehierarchization—Reorganizing gender? Dr. politavhandling i sosiologi, Norwegian University of Science and Technology, Trondheim.

Røvik, K.-A. (2003) 'The secrets of the winners: management ideas that flow', pp. 113-144. In Sahlin-Andersson, K. and Engwall, L. (eds) The Expansion of Management Knowledge: Carriers, Flows, and Sources. Stanford: Stanford University Press.

Sederblad, P. (ed) (2013) Lean $i$ arbetslivet [Lean in working life]. Stockholm: Liber.

Taylor, B. W. K. (2006) 'A feminist critique of Japanization: employment and work in consumer electronics', Gender, Work and Organization, 13: 317-337. 
Tengblad, S. and Oudhuis, M. (2014) Organisatorisk resiliens [Organizational resilience]. Lund: Studentlitteratur.

Thurén, B.-M. (2000) 'On force, scope, hierarchy. Concepts and questions for a crosscultural theorization of gender', Paper for the $4^{\text {th }}$ European Feminist Conference, Bologna.

Toivanen, S. and Landsbergis, P. A. (2013) 'Lean och arbetstagarnas hälsa' [Lean and workers' health], pp. 84-102. In Sederbland, P. (ed) Lean i arbetslivet. Stockholm: Liber.

Thompson, P. and Warhurst, C. (eds.) (1998) Workplaces of the Future. London: Macmillan Press.

West, C. and Zimmerman, D. H. (1987) 'Doing gender', Gender and Society, 1 (2): 125-151.

West, C. and Zimmerman, D. H. (2009) 'Accounting for doing gender', Gender and Society, 23: $112-122$.

Westgaard, R. H. and Winkel, J (2011) 'Occupational musculoskeletal and mental health: significance of rationalization and opportunities to create sustainable production systems-a systematic review', Applied Ergonomics, 42 (2): 261-296.

Wikberg-Nilsson, Å., Fältholm, Y. and Abrahamsson, L. (2009) 'The Future Factory-a concept designed by women and young people', Paper at IEA 2009, the $17^{\text {th }}$ World Congress on Ergonomics, Aug 9-14, 2009, Beijing.

Wikberg-Nilsson Å., Fältholm, Y. and Abrahamsson, L. (2010) 'Reframing practice through the use of personas', Reflective Practice, 11 (3): 285-298.

Willis, P. (1977) Learning to Labor. London: Saxon House.

Zanoni, P. (2011) 'Diversity in the lean automobile factory: doing class through gender, disability and age', Organization, 18 (1): 105-127.

\section{Endnotes}

1 In this article, "gender equality" refers to less gendered work organizations, that is, organizations with less gender stereotypes and less gender segregation and hierarchy (cf., Deutsch 2007; Lorber 2000; Martin 2011). In English, the concepts gender equality, equal opportunity, and gender equity are sometimes used to illustrate the connections to different theoretical traditions within gender studies (Nentwich 2006). In Swedish, there is only one term, "jämställdhet," and it does not have any given gender-theoretical base. The same term is used when talking about approaches based on sociobiology, women's standpoint, liberal individualism, liberal structuralism, radical structuralism, and social constructionism. In this text, I use the term gender equality mainly as a translation of the Swedish term "jämställdhet" (cf., Magnusson 1999), but with an emphasis of today's dominant view on gender equality in Sweden, which can be described as being close to a combination of radical structuralism and social constructionism with a touch of poststructuralism with the aim of moving toward something similar to Lorber's (2000), as well as my own, definition of a gender equal working life-a degendered working life.

2 Parts of this material have been published in Swedish in three book chapters and one book: 1) Abrahamsson, L (2014) 'När det omöjliga blev möjligt', in Grönlund, A (ed.). Glimtar av jämställdhet. Umeå: Borea, pp. 201-227. 2) Abrahamsson, L. (2013) 'Lean och jämställdhet. En longitudinell genusanalys av några svenska industriföretags arbete med att implementera lean', in Sederblad, P (ed). Lean i arbetslivet. Stockholm: Liber, pp. 275-297. 3) Abrahamsson, L. (2009) Att àterställa ordningen, Umeå: Borea. 4) Abrahamsson, L. (2006) 'Det mesta är sig likt, men ändå inte. En uppföljningsstudie av förändringsprojekt och jämställdhet i industriföretag', in Göransson, U and Sundin, E (ed.) Vad hände sen? Långsiktiga effekter av jämställdhetssatsningar under 1980- och 90-talen. VINNOVA-rapport 2006:08. Stockholm: VINNOVA, pp. 95-117. 
3 These groups can be related to two of Martin's (2011) categories: "male dominated" and "mixed gender." I divided the last one in two (one with gender segregation and one with gender mix). I did not include her third category, "female dominated," simply because there are extremely few such organizations in Swedish manufacturing and process industry.

${ }^{4}$ I use the concepts of restoring mechanism and restoring responses mainly as negative concepts. Here restoring the order in a work organization means a stability that is problematic and contraproductive for both gender equality (because it hinders change) and the functionality of the organization (because it hinders flexibility, mobility, and the ability to react on changes in the surrounding world). This means that organizational restoring should not be confused with organizational resilience, which is almost the opposite (cf., Tengblad and Oudhuis 2014). 